\title{
COPD exacerbations: definitions and classifications
}

\author{
S. Burge*, J.A. Wedzicha\#
}

COPD exacerbations: definitions and classifications. S. Burge, J.A. Wedzicha. (CERS Journals Ltd 2003.

ABSTRACT: Chronic obstructive pulmonary disease (COPD) is defined independently of exacerbations, which are largely a feature of moderate-to-severe disease. This article is the result of a workshop that tried to define exacerbations of COPD for use in clinical, pharmacological and epidemiological studies. The conclusions represent the consensus of those present.

This review describes definitions, ascertainment, severity assessments, duration and frequency, using varying sources of data including direct patient interview, healthcare databases and symptom diaries kept by patients in studies.

The best general definition of a COPD exacerbation is the following: an exacerbation of COPD is a sustained worsening of the patient's condition, from the stable state and beyond normal day-to-day variations that is acute in onset and may warrant additional treatment in a patient with underlying COPD.

A more specific definition for studies where a bacteriological cause of exacerbation is being studied is included, as well as simpler definitions for retrospective identification from database sources. Prospective diary card assessments are best recorded as changes from an agreed baseline, rather than absolute symptom severities. Diary cards identify many unreported exacerbations, which on average have similar severities to reported exacerbations. A scale for exacerbation severity is proposed that incorporates in- and outpatient assessments. Exacerbation duration, which also relates to severity, is defined from diary card reports. Healthcare utilisation is not an adequate substitute for severity, depending on many unrelated social and comorbidity factors. It is an outcome in its own right.

Eur Respir J 2003; 21: Suppl. 41, 46s-53s.
* Birmingham Heartlands Hospital, Birmingham and ${ }^{\#}$ Academic Unit of Respiratory Medicine, St Bartholomew's and Royal London School of Medicine, London, UK.

Correspondence: S. Burge

Birmingham Heartlands Hospital

Bordesley Green East

Birmingham B9 5SS

UK

Fax: 441217720292

E-mail: Sherwood.Burge@heartsol.wmids.nhs.uk

Keywords: Chronic obstructive pulmonary disease aetiology

definition

exacerbation

incidence

prevention

Received: August 212002

Accepted after revision: February 202003
Chronic obstructive pulmonary disease (COPD) and asthma are the two commonest causes of adult airflow obstruction. Asthma is differentiated from COPD by the variability of the airflow obstruction (i.e. exacerbations) while COPD is defined as "a chronic slowly progressive disease characterised by airflow obstruction that does not change markedly over several months..." [1]. COPD is therefore defined independently of exacerbations. Exacerbations are infrequent in early COPD and are largely a feature of moderate-to-severe disease [1]; even then, $20 \%$ of patients with moderate-to-severe disease had no exacerbations during the 3 yrs of the Inhaled Steroids in Obstructive Lung Disease in Europe (ISOLDE) study (fig. 1) [2-4].

Exacerbations are related to reduced quality of life (health effects) [5]. There is uncertainty as to whether exacerbations increase the rate of decline in forced expiratory volume in one second (FEV1) [6] or whether recovery to pre-exacerbation levels is the norm [7]. There is some evidence that exacerbations are more frequent in those with regular sputum production [8] and that regular sputum production is associated with accelerated FEV1 decline [8] and death from respiratory infection [9].

Interventions may affect the severity of individual exacerbations or the exacerbation frequency. A pharmacological intervention may reduce dyspnoea associated with an exacerbation changing what would have been a severe exacerbation to a mild exacerbation, but may have little effect on the actual exacerbation frequency. Thus, the individual exacerbation severity and frequency can be viewed as independent outcome

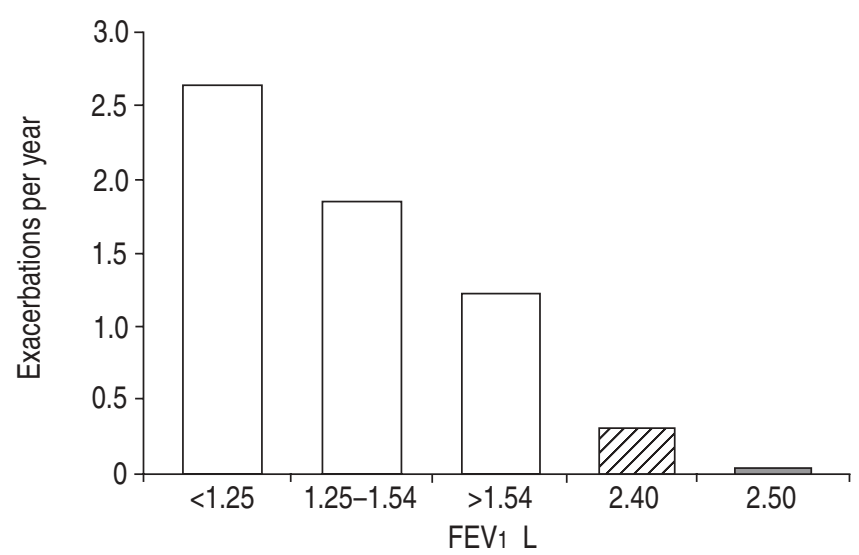

Fig. 1.- Incidence of exacerbations per year (mean) related to forced expiratory volume in one second $\left(\mathrm{FEV}_{1}\right)$ in the placebo arms of three 3-yr studies. The first three bars $(\square)$ are from the Inhaled Steroids in Obstructive Lung Disease in Europe (ISOLDE) study split into three equal-numbered groups [2-4]. Exacerbations for the ISOLDE trial and European Respiratory Society Study on Chronic Obstructive Pulmonary Disease ( $\square$ ) were defined as a worsening of respiratory symptoms that required treatment with oral corticosteroids or antibiotics, as judged by the general practitioner. The Copenhagen City Lung Study $(\mathscr{Z})$ defined exacerbations more broadly as an affirmative answer to "Have you, since your last visit, experienced more cough and phlegm?" This probably explains the slightly higher exacerbation rate than expected from the FEV1 values. 
measures and need separate consideration. Factors predicting exacerbation frequency included the number of exacerbations in the previous year $[5,10]$ and thus patients can be classified into frequent and infrequent exacerbators.

The high healthcare costs associated with exacerbations has led to a need for early recognition, diagnosis and treatment of exacerbations and, especially, identification of the patient at risk from frequent exacerbations. A good definition can be used in education programmes to increase patient awareness and recognition of exacerbations. A number of pharmacological interventions may reduce COPD exacerbation and thus there is a need for a standardised definition that can be generally applied to clinical trials.

A prerequisite for a COPD exacerbation is that the patient has known COPD. It is often difficult to separate COPD from other causes of airflow obstruction during the first documented episode, when a less precise initial diagnosis is preferable until the disease has been characterised. Patients with COPD often have comorbidities, which need to be excluded before deterioration in symptoms can be attributed to a COPD exacerbation. The commonest alternative diagnoses are heart failure, pulmonary embolism, rib fracture, pneumothorax, pneumonia and bronchial carcinoma. These other diagnoses should not be included within the definition of a COPD exacerbation. The definition of COPD is excluded when bronchiectasis is the principal cause for the airflow obstruction. The problem arises when thin-section, high-resolution computed tomography scans are applied to a clinically defined COPD population, when relatively minor degrees of bronchiectasis are frequently seen [11]. When the bronchiectasis is minor in relation to the airflow obstruction, patients should be left within the compass of COPD for the moment.

This article is the result of a workshop, which tried to define exacerbations of COPD for use in clinical, pharmacological and epidemiological studies using varying sources of data, including direct patient interview, healthcare databases and symptom diaries kept by patients in studies. The conclusions represent the consensus of those present.

\section{Defining an exacerbation of chronic obstructive pulmonary disease}

There is no generally agreed definition for an exacerbation of COPD, since exacerbations have a variety of causes and severities. It is the patient with COPD who usually seeks help for a deterioration in perceived health. It seems reasonable to use a definition that does not imply aetiology or severity. An amendment of the previous consensus definition [12] is recommended, as follows, to include exacerbations of similar severity where extra treatment was not sought: sustained worsening of the patient's condition from the stable state and beyond normal day-to-day variations that is acute in onset and may warrant additional treatment in a patient with underlying COPD.

This definition can be qualified for operational purposes to include: 1) requiring treatment with oral or parenteral corticosteroids; and 2) requiring treatment with an antibiotic. Several large COPD studies have used the definition "a worsening of respiratory symptoms, which required treatment with oral corticosteroids or antibiotics, or both" [2].

This definition also requires the patient to access healthcare where such treatment can be given, and is subject to the same underascertainment as other nondiary card sources. The incidence of exacerbations, so defined, depends on the severity of the underlying COPD. Its relation to pre-exacerbation FEV1 is shown in figure 1 , based on the placebo arms of three large studies. It is unclear whether the lack of recorded exacerbations
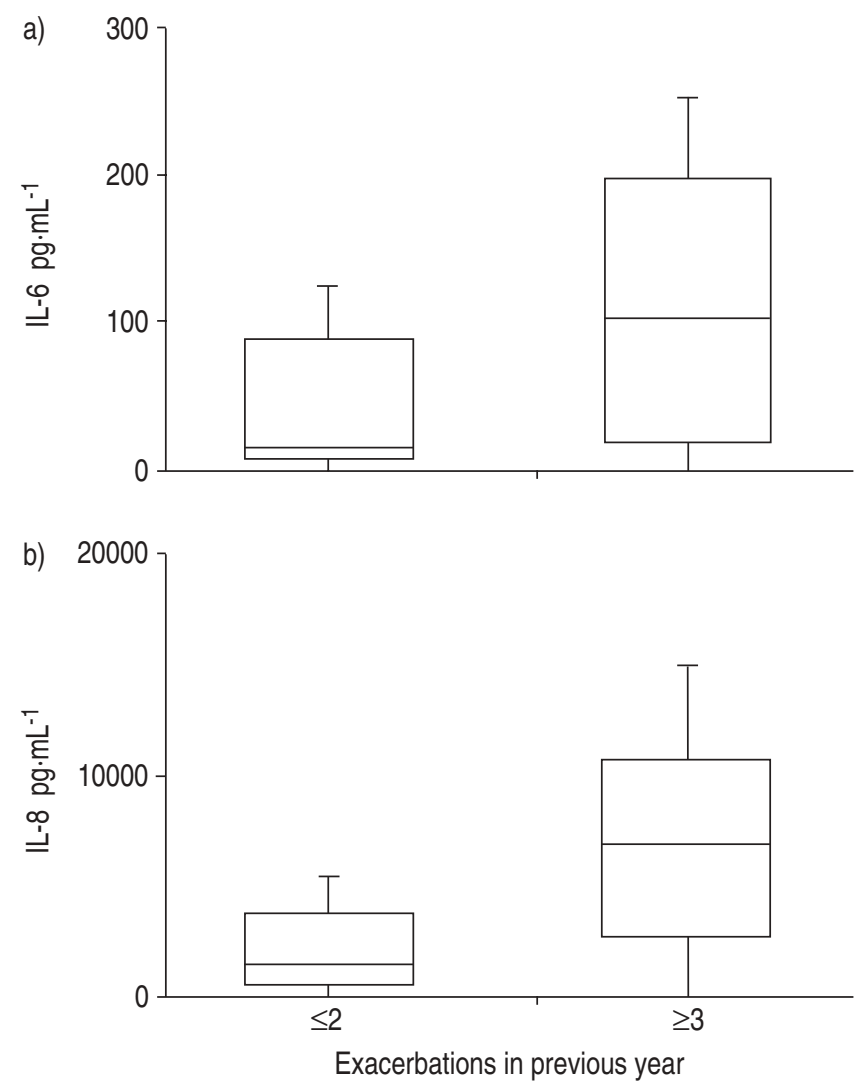

Fig. 2.-a) Median induced sputum levels of a) interleukin (IL)-6 and b) IL-8 in patients with frequent $(\geqslant 3$ exacerbations in the previous year, $n=23)$ and infrequent exacerbations $(\leqslant 2$ exacerbations in previous year, $\mathrm{n}=21)$. Boxes represent $95 \%$ confidence intervals and bars indicate interquartile ranges. Reproduced from [13] with permission.

in less-advanced disease is a result of the definition used or because exacerbations are genuinely rare in this group. A respiratory illness without increase in breathlessness is best defined as acute bronchitis rather than an exacerbation of COPD.

Some patients with moderate-to-severe COPD are prone to frequent exacerbations (three or more exacerbations per year) that are an important cause of hospital admission and readmission and thus have considerable impact on quality of life and daily activities [5]. Thus, this patient group of "frequent exacerbators" produces considerable health economic issues. They have similar FEV1 levels to patients with moderate-tosevere COPD with a history of less frequent exacerbations although the patients who have a history of frequent exacerbations have increased airway inflammatory markers, such as the cytokines interleukin (IL)-6 and -8 [13] (fig. 2). Frequent exacerbators also have increased airway bacterial colonisation with bacteria such as Haemophilus influenzae and Streptococcus pneumoniae in the stable state [14]. Patients colonised by $H$. influenzae in the stable state report more symptoms and increased sputum purulence at exacerbation than those not colonised, suggesting that the presence of bacterial colonisation may lead to more severe exacerbations [14]. Thus, the increased airway inflammation in frequent exacerbators may lead to faster decline in lung function [6].

\section{Definitions related to specific aetiologies of an exacerbation}

The principal identified causes of COPD exacerbations include bacterial [15] and viral infections [16, 17], pollution 
Table 1.-Definitions of chronic obstructive pulmonary disease exacerbations developed for studies of antibiotics

\begin{tabular}{|c|c|c|}
\hline Type & Symptoms & $\begin{array}{l}\text { Additional minor } \\
\text { symptoms }\end{array}$ \\
\hline
\end{tabular}

1 An increase in sputum volume

An increase in sputum purulence

An increase in dyspnoea

2 Any two from

An increase in sputum volume

An increase in sputum purulence

An increase in dyspnoea

3

A single symptom from

An increase in sputum volume

An increase in sputum purulence

An increase in dyspnoea

Plus at least one minor symptom
Sore throat or nasal discharge within past 5 days
Fever without other cause
Increased wheezing
Increased cough
Increased respiratory rate $>20 \%$ above baseline
Increased heart rate $>20 \%$ above baseline

events [18, 19], cold weather [20] and interruption of regular treatment [21]. Some definitions are appropriate when particular aetiologies are being studied.

Definitions relevant to bacterial infections. The best-studied COPD exacerbation definitions were developed for studies of antibiotics for which bacterial exacerbations were required. Antibiotics were helpful for type 1 and less so for type 2 of the classification seen in table 1 [22].

Using this definition, health-status score is closely related to the exacerbation frequency, with worse health status in patients with frequent exacerbations [5]. Further work also showed that dyspnoea is the most common and important symptom of an exacerbation and that the fall in lung function at exacerbation is related to the presence of dyspnoea at exacerbation [16]. Thus, these studies provide some validation of the use of this definition. The significance of the minor criteria of type 3 (table 1) has never been formally studied.

The differentiation by sputum colour has had variable significance. Careful selective microbiology has shown significant bacterial cultures in $85 \%$ of those with purulent or mucopurulent sputum and $38 \%$ in mucoid sputum, the same proportion as in those whose sputum was originally purulent when restudied in the stable state. A standardised colour chart is available for this classification [23], which separates exacerbations that can be safely managed without an antibiotic from those requiring an antibiotic [15]. Sputum colour can be reproducibly classified by trained technicians using a standardised colour chart.

An exacerbation associated with purulent sputum production will be associated with a large bacterial load [15], while an exacerbation associated with a cold or upper respiratory symptoms will be viral in origin [16, 24]. Virally triggered exacerbations treated similarly with antibiotics and corticosteroids have longer recovery periods than nonviral exacerbations [24] (fig. 3), and thus, exacerbations of different aetiology may behave differently with interventions. One study showed that airway inflammatory markers were raised in sputum that contained $H$. influenzae or Moraxella catarrhalis compared with sputum samples where bacterial pathogens were not detected [25]. The cause may be important to identify when specific interventions are being used to target triggers of exacerbations, e.g. antibiotics or antiviral agents. Exacerbations

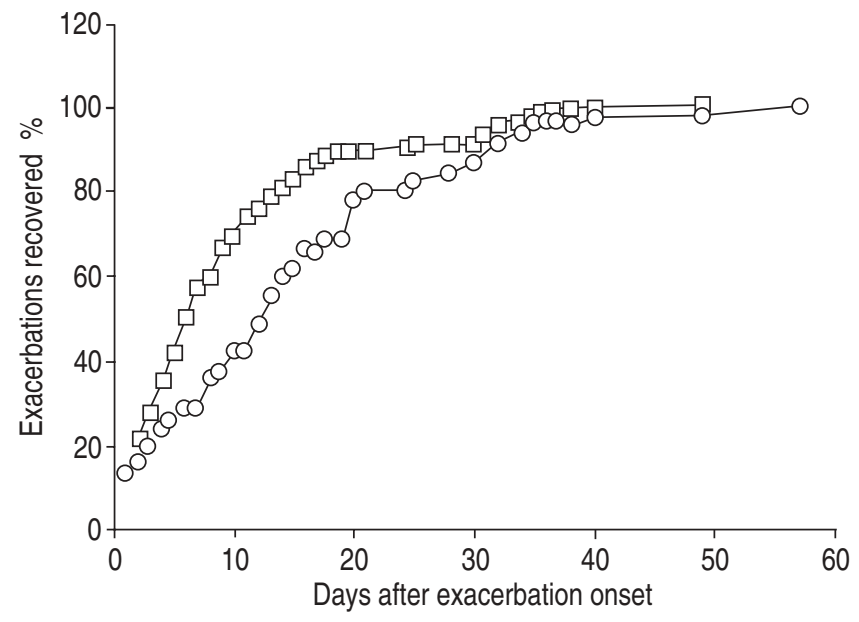

Fig. 3.-Graph showing the cumulative percentage of viral $(\bigcirc)$ and nonviral $(\square)$ exacerbations recovering symptomatically with respect to time after onset during 150 chronic obstructive pulmonary disease exacerbations ( $\mathrm{p}=0.006)$ Reproduced from [24] with permission.

associated with viral infections are associated with more airway inflammation than nonviral ones [16, 24, 26], and thus, it would be expected that these exacerbations may be more responsive to therapy with anti-inflammatory agents. Again aetiology can be partially determined from the diary card and this emphasises the importance of careful monitoring of patients to detect exacerbations.

Others. There are no available definitions based on sputum culture, as positive cultures are common in the stable state. Similarly, viral isolates are found in $\sim 15 \%$ of patients with stable COPD making a positive viral identification alone an unsuitable method of defining an exacerbation. Health-related quality of life declines with exacerbations but cannot be reliably measured sufficiently frequently (e.g. daily) to form the basis for a definition [5]. Changes in FEV1 or peak expiratory flow (PEF), when measured daily, are insensitive in the individual diagnosis of exacerbations not requiring hospital admission (median change in PEF $8.6 \mathrm{~L} \cdot \mathrm{min}^{-1}$, FEV1 $24 \mathrm{~mL}$ ); the individual between-days measurement variation is larger than the mean change during an exacerbation [27]. The chest radiograph usually shows no different features during an exacerbation and so cannot be used. Airway inflammatory markers increase at exacerbations but these rises cannot be used as markers of severity, since there are no relationships between levels of induced sputum cytokines IL-6 and IL-8 at exacerbation and physiological changes or recovery times at exacerbation [26]. Systemic inflammatory markers such as C-reactive protein, plasma fibrinogen and IL-6 also increase acutely with COPD exacerbation and, although these rises are higher in the presence of bacterial or viral infection $[13,15,28$, 29], direct relationships have not been found between these changes, exacerbation time course and severity. There are no evaluated definitions based on exhaled breath markers of inflammation, such as carbon monoxide.

\section{Ascertainment of an exacerbation}

Exacerbations can be ascertained retrospectively by patient interview or from records of treatment such as healthcare databases. Prospective identification requires the patient to keep a diary card. Exacerbation frequency using different data sources should not be compared; prospective diary card 
definitions are likely to identify more exacerbations than retrospective sources.

\section{Ascertainment of exacerbations from databases}

It is possible to make a retrospective diagnosis of a COPD exacerbation from information held on health-related databases. Any hospital admission with a primary diagnosis of COPD exacerbation could be so classified. Individuals may have several health-related encounters over a short period of time, sometimes with diagnoses varying between COPD, bronchitis and sometimes asthma, from different physicians in emergency departments, offices and hospitals. The group agreed that in the known presence of COPD these could be amalgamated into one episode, provided that the interval between adjacent contacts is $<14$ days. One episode would equate to one exacerbation defined from prospectively collected data.

Ascertainment of exacerbations using less specific healthcare utilisation data, e.g. visits to primary-care physicians or change in the use of regular medication [12], were often used in earlier studies where COPD exacerbation was not the primary outcome. They are less satisfactory and not recommended.

\section{Daily diary cards}

Patient-kept, daily diary cards increase the precision of exacerbation detection but limit the number of subjects suitable for study, as a degree of cognitive (and visual) skills are required, as well as the willingness to complete daily records for $\geqslant 12$ months. There is evidence that patients do not report all exacerbations that are suggested by prospective diary-card recording [5]. Most experience has been obtained with diary cards that relate symptoms to the usual baseline state rather than to score severity. The individuals baseline state should be agreed with the patient after training [5]. Several symptoms can be scored; scoring is best done after the morning deterioration has stabilised, perhaps best at 10:00 h. One study requires a deterioration in at least one symptom from breathlessness, sputum volume or sputum purulence, with at least a second symptom that could additionally include nasal discharge/congestion, wheeze, sore throat or cough [16].

At least two symptoms deteriorating on two successive days constituted the start of an exacerbation. Increased breathlessness should be the only obligatory symptom, but at least one other symptom should also deteriorate. The original diary card only included the possibility of symptoms deteriorating or staying the same, posing a statistical problem with the definition for the end of an exacerbation. A preferable scale is shown in table 2.

An exacerbation can be defined as "d" or "e" occurring for at least two consecutive days. Increased bronchodilator use is not helpful in defining COPD exacerbations, as unlike the situation in asthma, most patients with more severe COPD take bronchodilators several times a day, even on relatively good days. Changes in symptoms (or lung function) following

Table 2. - A scale suitable for daily diary card assessment of chronic obstructive pulmonary disease symptoms

a) My breathing is much better than usual

b) My breathing is better than usual

c) My breathing is the same as usual

d) My breathing is worse than usual

e) My breathing is much worse than usual bronchodilators are minor compared with asthma and are unlikely to confound symptom-severity scoring.

Use of the diary cards has shown that $\sim 50 \%$ of exacerbations are unreported to the research team, despite the provision of considerable encouragement. There were no differences in FEV1, change in PEF at exacerbation or in the major symptoms of exacerbations (dyspnoea, increased sputum volume and purulence) between the reported and unreported exacerbations [5]. The only differences found in the two groups were that reported exacerbations were associated with increased cough but a lower incidence of increased wheeze.

\section{Assessing the severity of an exacerbation}

The underlying severity of the COPD is the major factor determining exacerbation severity; large changes in disease severity are unusual in exacerbations identified from diary cards and often imply alternative diagnoses, such as pneumonia or major pulmonary embolism. There are no established criteria for assessing severity in less severely ill patients not requiring hospital assessment. In published studies, treatment with oral or parenteral corticosteroids constituted a more severe exacerbation (severity "b") and that others were classified as mild/moderate (severity "a"). A cohort study showed that exacerbations treated with steroids were more severe, in that they were associated with larger falls in PEF, had a longer PEF recovery time and a longer symptom score recovery time (J.A. Wedzicha, St Bartholomew's and Royal London School of Medicine, London, UK, personal communication).

Those requiring hospital admission, or at least hospital assessment, can be usefully categorised for severity, based on the presence or absence of respiratory failure, using standard criteria based on arterial blood-gas measurement while breathing room air.

A classification of severity incorporating studies of outpatients without blood-gas analysis and those assessed with blood gases is suggested in table 3 .

\section{Severity from databases}

For those with known COPD, an entry with an oral or parenteral corticosteroid prescription could be classified as severe, while those with a respiratory-related antibiotic could be classified as a mild/moderate exacerbation, provided there was no alternative reason for the prescription. A better alternative would be to define relapses separately from exacerbation frequency. A relapse could be defined when the exacerbation definition is reached within 28 days of a previous exacerbation.

\section{Defining the duration of an exacerbation}

Patients with greater falls in lung function or an increase in symptom scores at exacerbation have a longer length of the respective recovery times for these parameters and thus exacerbation length can be used as a marker of severity. Startand-stop days are needed. Length of hospital stay is not a good surrogate for duration as it is dependent on many other factors and very short hospital stays may be associated with worse outcomes [30]. The start of an exacerbation could be defined from the date of first healthcare contact; the end from the date of return to the pre-exacerbation health state, which could be ascertained from a questionnaire, but would be defined more accurately from continuously kept daily diary cards. In COPD patients most exacerbations have a relatively short prodromal phase [27], and thus the onset of the exacerbation can be determined. The end of an exacerbation is 
Table 3. - A scale for exacerbation severity incorporating exacerbations managed at home and in hospital

\begin{tabular}{|c|c|}
\hline Mild & $\begin{array}{l}\text { An exacerbation treated with antibiotics but no systemic corticosteroid. If no blood gases are available the } \\
\text { absence of respiratory failure is assumed }\end{array}$ \\
\hline Moderate & $\begin{array}{l}\text { An exacerbation treated with parenteral corticosteroids with or without an antibiotic. If no blood gases are } \\
\text { available the absence of respiratory failure is assumed }\end{array}$ \\
\hline Severe & $\begin{array}{l}\text { Type } 1 \text { respiratory failure with hypoxaemia but no carbon dioxide retention or acidosis; } P \text { a }, \mathrm{O}_{2}<8 \mathrm{kPa}(60 \mathrm{mmHg}) \\
\text { and } \mathrm{Pa}_{\mathrm{a}} \mathrm{CO}_{2}<6 \mathrm{kPa}(45 \mathrm{mmHg})\end{array}$ \\
\hline Very severe & $\begin{array}{l}\text { Type } 2 \text { respiratory failure, compensated with hypoxia, carbon dioxide retention but no acidosis; } P \text { a }, \mathrm{O}_{2}<8 \mathrm{kPa} \\
(60 \mathrm{mmHg}), \mathrm{Pa}, \mathrm{CO}_{2}>6 \mathrm{kPa}(45 \mathrm{mmHg}) \text { and hydrogen ion concentration }<44 \mathrm{nM}(\mathrm{pH}>7.35)\end{array}$ \\
\hline Life-threatening & $\begin{array}{l}\text { Type } 2 \text { respiratory failure, decompensated with acidosis and carbon dioxide retention; } P \mathrm{a}, \mathrm{CO}_{2}>6 \mathrm{kPa}(45 \mathrm{mmHg}) \\
\text { and hydrogen ion concentration }>44 \mathrm{nM}(\mathrm{pH}<7.35)\end{array}$ \\
\hline
\end{tabular}

$\mathrm{Pa}, \mathrm{O}_{2}$ : arterial oxygen tension; $\mathrm{Pa}, \mathrm{CO}_{2}$ : arterial carbon dioxide tension.

more difficult to define. A rolling 3-day mean symptom score returning to the pre-exacerbation level has been used [5, 27]. However, at 35 and 91 days, a number of exacerbations have not returned to baseline and this can make recovery time difficult to compute [27]. In one study [27] at 35 days, $25 \%$ of patients had not recovered their PEF to baseline, and in $14 \%$ symptoms had not recovered, while at 91 days $7 \%$ of patients had not recovered their PEF to baseline. There is a real problem in defining the number of exacerbations in a patient who initially improves but then deteriorates when acute treatment is withdrawn. Many end up taking a further course of systemic corticosteroids and further antibiotics. Those studying databases have suggested that new treatment with antibiotics or systemic corticosteroids $>14$ days after the start of an exacerbation constitute a second exacerbation, although this classification is arbitrary.

\section{Outcome variables based on exacerbation frequency}

Exacerbation frequency is seasonal in many climates and particularly related to influenza and other viral epidemics. Any comparisons need to follow the subjects over exactly the same periods of time and place. Studies covering periods of 12 months help overcome this. Shorter studies sometimes use time to first exacerbation as an outcome; this outcome is particularly liable to time/place confounding and takes no account of the interval from last exacerbation to trial entry.

Many treatments probably reduce the severity of exacerbations more than the frequency [31]. Severity should be assessed for each exacerbation.

Dropouts often confound exacerbation frequency. Those dropping out usually have increased exacerbation frequency compared with those remaining in a trial, as exacerbations often require treatments, such as oral corticosteroids for $>10$ days, which may be an exclusion criterion from a study. This was a particular problem in the ISOLDE trial where the benefits in terms of exacerbation frequency reduction, FEV1 decline reduction and slowing the rate of decline in health-related quality of life were all much greater in those withdrawing prematurely than those completing the study [32]. Exacerbations then need reporting as number/time. If time in the trial is the denominator, a dropout shortly after trial entry will result in a spuriously high exacerbation frequency (e.g. occasionally $\left.>50 \cdot \mathrm{yr}^{-1}\right)$. Differential dropouts may also introduce a season/ place bias. It may be better to follow-up all patients who have violated trial treatment restrictions to the planned end of the trial.

\section{Assessments related to healthcare costs}

Healthcare costs are not a useful measure of exacerbation severity and should not be used as such. Hospital admission is often precipitated by a lack of social support and comorbidities. Many similarly sick patients can be cared for more cheaply with hospital outreach schemes. An assessment used to select patients unsuitable for hospital at-home treatment, which combines severity with comorbidity and social factors, is shown in table 4. Healthcare costs, however, are important to study and are likely to be reduced by interventions that reduce hospital admissions. Costing studies can divide patients having exacerbations as shown in table 5. The hospital admission category can be subdivided into those requiring standard ward treatment and those requiring intensive care nursing, where the costs increase substantially. As intensive care admission may not be available to all those who may benefit, an end-point of those meeting criteria for intubation can be used, even if this was not done [33]. The criteria for intubation in one study [33] are shown in table 6. An assessment used to select patients unsuitable for hospital at-home treatment,

Table 4. - Criteria excluding hospital at home for a patient with an exacerbation of chronic obstructive pulmonary disease

Respiratory rate $>25 \cdot \mathrm{min}^{-1}$

Pulse rate $>110 \cdot \mathrm{min}^{-1}$

$P \mathrm{a}, \mathrm{O}_{2}<8 \mathrm{kPa}(60 \mathrm{mmHg})$

Abnormal chest radiograph

Serious concomitant disease

Altered mental state

Living alone

$\mathrm{Pa}, \mathrm{O}_{2}$ : arterial oxygen tension

Table 5. - Classification of chronic obstructive pulmonary disease exacerbations by healthcare utilisation

a) Self-managed at home

b) Treatment by family physician at home, or at home after a hospital clinic or emergency room visit

c) Hospital at home (outreach)

d) Hospital admission, general ward

e) Hospital admission, intensive care

Table 6. - Criteria for intubation (a more reliable measure of those requiring intensive care)

Hydrogen ions $>62 \mathrm{nM}, \mathrm{pH}<7.2$

Hydrogen ions 56-62 nM, pH 7.2-7.25 on two occasions $1 \mathrm{~h}$ apart

$P \mathrm{a}, \mathrm{CO}_{2}>8 \mathrm{kPa}(60 \mathrm{mmHg})$ and Glasgow coma scale $<8$ (hypercapnic coma)

$P a, \mathrm{O}_{2}<6 \mathrm{kPa}(45 \mathrm{mmHg})$ despite maximum tolerated inspiratory oxygen fraction

Cardiorespiratory arrest

For any of the following occurring within 14 days of admission. $\mathrm{Pa}, \mathrm{CO}_{2}$ arterial carbon dioxide tension; $\mathrm{Pa}, \mathrm{O}_{2}$ : arterial oxygen tension. Adapted from data from [33]. 
Table 7.-Confounding factors related to the incidence of chronic obstructive pulmonary disease exacerbations

\begin{tabular}{lc}
\hline Factor & Reference \\
\hline Sex & {$[34]$} \\
Season, weather, viral outbreaks & {$[18-20,35]$} \\
Influenza vaccination & {$[35]$} \\
Pneumococcal vaccination & {$[36]$} \\
Pulmonary rehabilitation & {$[37]$} \\
Regular inhaled corticosteroids & {$[2,31]$} \\
Regular long-acting bronchodilators & {$[38,39]$} \\
Regular tiotropium & {$[40,41]$} \\
Mucolytics/antioxidants & {$[42]$} \\
Specific antibiotic used to treat initial & {$[43]$} \\
$\quad$ exacerbation (particularly activity & \\
against Haemophilus influenzae) & {$[43]$} \\
Current smoking & {$[43]$} \\
\hline Ischaemic heart disease &
\end{tabular}

combining severity with comorbidities and social factors, is shown in table 7.

\section{Confounding variables}

There are many factors that have been shown to influence COPD exacerbation rates or severity (table 7), but few studies identify the majority of these. They should be recorded or controlled in intervention studies. Exacerbations of COPD have a large winter peak in temperate climates, accounting for much of the increased "winter pressures" of increased medical hospital admissions [39]. Females are more likely to be admitted to hospital for COPD exacerbations, and have increased risks from smoking compared with males. In an analysis of the Copenhagen City Heart Study, females had a 1.5-fold increased risk of admission after controlling for smoking; the risk was 3.6-fold in the Glostrup population studies [34]. Continuing smokers had a 1.47 -fold higher relapse rate in one study [43]. Those with comorbidities, particularly ischaemic heart disease, are more likely to have a relapse after an exacerbation (odds ratio 5.6 [43]).

Influenza vaccinations have been shown to reduce respiratory illnesses the following winter. One randomised study [35] in Minneapolis-St Paul, MN, USA, showed a 25\% reduction compared with placebo in working adults. In a database study of those $>65$ ys of age, the same group found a reduction in admissions due to all chronic respiratory illnesses by $27-39 \%$ depending on the year, in addition to a reduction of pneumonia and influenza by $48-57 \%$ [35]. In a similar study, elderly patients receiving pneumococcal vaccination had a reduced relative risk of 0.57 for hospital pneumonia admissions, with an additive effect of influenza vaccination [35]. A prospective, nonrandomised study in Stockholm, Sweden, supported these findings with a total mortality reduction of $57 \%$ [44].

One randomised study of outpatient pulmonary rehabilitation [37] showed that days in hospital were reduced from 21 to 10.4 in those randomised to rehabilitation in the following year, but no difference in the chance of admission over the same period (40 versus $41 \%$ ) was observed, suggesting an effect on exacerbation severity reduction.

A number of pharmaceutical treatments have influenced exacerbation severity or rate. Several randomised studies of inhaled corticosteroids in patients with more severe COPD have reduced exacerbations by $\sim 25 \%[2,31]$, with some evidence of exacerbation severity being influenced more than exacerbation rate [31] and increased exacerbations shortly after withdrawal of inhaled corticosteroids [21]. These results have been supported by database studies [45], which also show that the risk of death is reduced in those picking up regular prescriptions compared with less regular treatment [46]. Bronchodilator trials have also shown exacerbation reductions, perhaps greater for those taking long-acting anticholinergic therapy compared with long-acting $\beta$-adrenergic agonists. Oncedaily inhaled tiotropium $18 \mu \mathrm{g}$ reduced at least one exacerbation over 12 months by $14 \%$ compared with placebo and exacerbation frequency by $20 \%$ [40]; $42 \%$ of this group were on regular inhaled corticosteroids and $7 \%$ on regular oral steroids. In a similar comparison with ipratropium bromide, tiotropium reduced exacerbation frequency by $24 \% ; 80 \%$ of this group were on regular inhaled corticosteroids suggesting that the effect was additional to the corticosteroid effect [41]. The published evidence for long-acting $\beta$-adrenergic agonists is less good and is based on 12-week studies where exacerbators were reduced from $33 \%$ on placebo to $21 \%$ on salmeterol [38]. A similar study including a group randomised to salmeterol and ipratropium showed an additional effect of the ipratropium, reducing (undefined) exacerbations from $36 \%$ on placebo to $13 \%$ on the combination [39]. The Trial of Inhaled Steroids and Long-acting $\beta_{2}$-Agonists study, a 1-yr study [47], has shown a significant exacerbation reduction with salmeterol alone. A quantitative systematic review of $N$-acetylcysteine showed a reduction in exacerbation rate from $69 \%$ on placebo to $51 \%$ on $\mathrm{N}$-acetylcysteine, a relative benefit of 1.56 [42].

The choice of antibiotic during an exacerbation may alter the risk and timing of subsequent relapse. In a Veterans Affairs retrospective cohort study, patients treated with amoxicillin had significantly more relapses than those treated with other antibiotics (54 versus 19\%) [43]. Antibiotics eradicating $H$. influenzae, such as gemifloxacin have reduced the interexacerbation interval (results from the Gemifloxacin Long-term Outcomes in Bronchitis Exacerbations Study; R. Wilson, Royal Brompton Hospital, London, UK, personal communication).

\section{Prevention}

Influenza and pneumococcal vaccination, regular inhaled corticosteroid prescription, mucolytics, exacerbation antibiotic therapy, current smoking and lack of pulmonary rehabilitation are all factors associated with more frequent exacerbations, which are amenable to change. Some of these factors were studied in patients following hospital discharge with a COPD exacerbation [48]. Remediable factors were found in the majority, including lack of influenza vaccination $(28 \%)$, no pulmonary rehabilitation $(86 \%)$, poor inhaler technique $(43 \%)$ and current smoking $(26 \%)$.

\section{Research questions related to chronic obstructive pulmonary disease exacerbation definition}

There is concern that the exacerbations identified from daily diary cards may be different in character, aetiology or severity from those seen in admitted patients. Patients with diary card-defined exacerbations should be investigated at the time of the exacerbation with lung function tests including lung volumes, physiological dead space and respiratory drive.

If diary cards measure symptom severity, rather than symptom change as recommended above, the limits of variation of individual daily symptom scoring should be established, to separate changes due to spontaneous variation from true exacerbations. Factors that may separate exacerbations with different trigger factors should be defined.

Chronic obstructive pulmonary disease exacerbations defined from databases need validation in the same manner as diary card-defined exacerbations. The separation of episodes (new 
exacerbations) from continuing single exacerbations from databases needs validation.

\section{References}

1. British Thoracic Society. BTS guidelines for the management of chronic obstructive pulmonary disease. The COPD Guidelines Group of the Standards of Care Committee of the BTS. Thorax 1997; 52: Suppl. 5, S1-S28.

2. Burge PS, Calverley PM, Jones PW, Spencer S, Anderson JA, Maslen TK. Randomised, double blind, placebo controlled study of fluticasone propionate in patients with moderate to severe chronic obstructive pulmonary disease: the ISOLDE trial. BMJ 2000; 320: 1297-1303.

3. Vestbo J, Sorenson T, Lange P, Brix A, Torre P, Viskum K. Long-term effect of inhaled budesonide in mild and moderate chronic obstructive pulmonary disease: a randomised controlled trial. Lancet 1999; 353: 1819-1823.

4. Pauwels RA, Lofdahl CG, Laitinen LA, et al. Long-term treatment with inhaled budesonide in persons with mild chronic obstructive pulmonary disease who continue smoking. European Respiratory Society Study on Chronic Obstructive Pulmonary Disease. N Engl J Med 1999; 340: 1948-1953.

5. Seemungal TA, Donaldson GC, Paul EA, Bestall JC, Jeffries DJ, Wedzicha JA. Effect of exacerbation on quality of life in patients with chronic obstructive pulmonary disease. Am J Respir Crit Care Med 1998; 157: 1418-1422.

6. Kanner RE, Anthonisen NR, Connett JE. The Lung Health Study Research Group. Lower respiratory illnesses promote FEV1 decline in current smokers but not ex-smokers with mild chronic obstructive pulmonary disease. Am J Respir Crit Care Med 2001; 164: 358-364.

7. Fletcher $\mathrm{C}$, Peto R. The natural history of chronic airflow obstruction. BMJ 1977; 1: 1645-1648.

8. Vestbo J, Prescott E, Lange P. Association of chronic mucus hypersecretion with FEV1 decline and chronic obstructive pulmonary disease morbidity. Copenhagen City Heart Study Group. Am J Respir Crit Care Med 1996; 153: 1530-1535.

9. Prescott E, Lange P, Vestbo J. Chronic mucus hypersecretion in COPD and death from pulmonary infection. Eur Respir J 1995; 8: 1333-1338.

10. Ball P, Harris JM, Lowson D, Tillotson G, Wilson R. Acute infective exacerbations of chronic bronchitis. QJM 1995; 88: $61-68$.

11. O'Brien C, Guest PJ, Hill SL, Stockley RA. Physiological and radiological characterisation of patients diagnosed with chronic obstructive pulmonary disease in primary care. Thorax 2000; 55: 635-642.

12. Rodriguez-Roisin R. Toward a consensus definition for COPD exacerbations. Chest 2000; 117: Suppl. 2, 398S-401S.

13. Bhowmik A, Seemungal TA, Sapsford RJ, Wedzicha JA. Relation of sputum inflammatory markers to symptoms and lung function changes in COPD exacerbations. Thorax 2000; 55: 114-120.

14. Patel IS, Seemungal TA, Wilks M, Lloyd Owen S, Donaldon GC, Wedzicha JA. Relationship between bacterial colonization and the frequency, character and severity of COPD exacerbations. Thorax 2002; 57: 759-764.

15. Stockley RA, O'Brien C, Pye A, Hill SL. Relationship of sputum color to nature and outpatient management of acute exacerbations of COPD. Chest 2000; 117: 1638-1645.

16. Seemungal TA, Harper-Owen R, Bhowmik A, Jeffries DJ, Wedzicha JA. Detection of rhinovirus in induced sputum at exacerbation of chronic obstructive pulmonary disease. Eur Respir J 2000; 16: 677-683.

17. Greenberg SB, Allen M, Wilson J, Atmar RL. Respiratory viral infections in adults with and without chronic obstructive pulmonary disease. Am J Respir Crit Care Med 2000; 162: 167.

18. Ministry of Health. Mortality and morbidity during the
London fog of December 1952. Report No. 95 on Public Health and Medical Subjects. London, Ministry of Health, 1954.

19. World Health Organization. Acute effects on health of smog episodes. Copenhagen, World Health Organization, 1992.

20. Donaldson GC, Seemungal TA, Jeffries DJ, Wedzicha JA. Effect of environmental temperature on symptoms, lung function and mortality in COPD patients. Eur Respir J 1999; 13: 844-849.

21. Jarad NA, Wedzicha JA, Burge PS, Calverley PM. An observational study of inhaled corticosteroid withdrawal in stable chronic obstructive pulmonary disease. ISOLDE Study Group. Respir Med 1999; 93: 161-166.

22. Anthonisen NR, Manfreda J, Warren CP, Hershfield ES, Harding GK, Nelson NA. Antibiotic therapy in exacerbations of chronic obstructive pulmonary disease. Ann Intern Med 1987; 106: 196-204.

23. Stockley RA, Bayley D, Hill SL, Hill AT, Crooks S, Campbell EJ. Assessment of airway neutrophils by sputum colour: correlation with airways inflammation. Thorax 2001; 56: $366-372$.

24. Seemungal TA, Harper-Owen $\mathrm{R}$, Bhowmik $\mathrm{A}$, et al. Respiratory viruses, symptoms and inflammatory markers in acute exacerbations and stable chronic obstructive pulmonary disease. Am J Respir Crit Care Med 2001; 164 : $1618-1623$.

25. Sethi S, Muscarella K, Evans N, Klingman KL, Grant BJ, Murphy F. Airway inflammation and aetiology of acute exacerbations of chronic bronchitis. Chest 2000; 118: 15571565 .

26. Gravil JH, Al-Rawas OA, Cotton MM, Flanigan U, Irwin A, Stevenson RD. Home treatment of exacerbations of chronic obstructive pulmonary disease by an acute respiratory assessment service. Lancet 1998; 351: 1853-1855.

27. Seemungal TA, Donaldson GC, Bhowmik A, Jeffries DJ, Wedzicha JA. Time course and recovery of exacerbations in patients with chronic obstructive pulmonary disease. Am J Respir Crit Care Med 2000; 161: 1608-1613.

28. Wedzicha JA, Seemungal TA, MacCallum PK, et al. Acute exacerbations of chronic obstructive pulmonary disease are accompanied by elevations of plasma fibrinogen and serum IL-6 levels. Thromb Haemost 2000; 84: 210-215.

29. Dentener MA, Creutzberg EC, Schols AM, et al. Systemic anti-inflammatory mediators in COPD: increase in soluble interleukin I receptor II during treatment of exacerbations. Thorax 2001; 56: 721-726.

30. Sin DD, Tu JV. Are elderly patients with obstructive airway disease being prematurely discharged? Am J Respir Crit Care Med 2000; 161: 1513-1517.

31. Paggiaro PL, Dahle R, Bakran I, Frith L, Hollingworth K, Efthimiou J. Multicentre randomised placebo-controlled trial of inhaled fluticasone propionate in patients with chronic obstructive pulmonary disease. International COPD Study Group. Lancet 1998; 351: 773-780.

32. Calverley PM, Spencer S, Willits L, Burge PS, Jones PW. Withdrawal from treatment as an outcome in the ISOLDE study of chronic obstructive pulmonary disease. Chest 2003; (In press).

33. Plant PK, Owen JL, Elliott MW. Early use of non-invasive ventilation for acute exacerbations of chronic obstructive pulmonary disease on general respiratory wards: a multicentre randomised controlled trial. Lancet 2000; 355: 1931-1935.

34. Prescott E, Bjerg AM, Andersen PK, Lange P, Vestbo J. Gender difference in smoking effects on lung function and risk of hospitalization for COPD: results from a Danish longitudinal population study. Eur Respir J 1997; 10: 822827.

35. Nichol KL, Margolis KL, Wuorenma J, von Sternberg T. The efficacy and cost effectiveness of vaccination against influenza among elderly persons living in the community. $N$ Engl J Med 1994; 331: 778-784.

36. Nichol KL, Baken L, Wuorenma J, Nelson A. The health 
and economic benefits associated with pneumococcal vaccination of elderly persons with chronic lung disease. Arch Intern Med 1999; 159: 2437-2442.

37. Griffiths TL, Burr ML, Campbell IA, et al. Results at 1 year of outpatient multidisciplinary pulmonary rehabilitation: a randomised controlled trial. Lancet 2000; 355: 362-368.

38. Mahler DA, Donohue JF, Barbee RA, et al. Efficacy of salmeterol xinafoate in the treatment of COPD. Chest 1999; 115: 957-965.

39. de la Iglesia MF, Pellicer VC, Ramos PV, Nicholas MR, Pita FS, Diz-Lois MF. Chronic obstructive pulmonary disease and the seasons of the year. Arch Bronchopneumol 2000; 36: 84-89.

40. Casaburi R, Mahler DA, Jones PW, et al. A long-term evaluation of once daily inhaled tiotropium in chronic obstructive pulmonary disease. Eur Respir J 2002; 19: 217224.

41. Vincken W, van Noord JA, Greefhorst AP, et al. Improved health outcomes in patients with COPD during 1 year's treatment with tiotropium. Eur Respir J 2002; 19: 209-216.

42. Stey C, Steurer J, Bachmann S, Medici TC, Tramer MR. The effect of oral $\mathrm{N}$-acetylcysteine in chronic bronchitis: a quantitative systematic review. Eur Respir J 2000; 16: 253-262.

43. Adams SG, Melo J, Luther M, Anzueto A. Antibiotics are associated with lower relapse rates in outpatients with acute exacerbations of COPD. Chest 2000; 117: 1345-1352.

44. Christenson B, Lundbergh P, Hedlund J, Ortqvist A. Effect of a large scale intervention with influenza and 23-valent pneumococcal vaccines in adults aged 65 years or older: a prospective study. Lancet 2001; 357: 1008-1011.

45. Sin DD, Tu JV. Inhaled corticosteroids and the risk of mortality and readmission in elderly patients with chronic obstructive pulmonary disease. Am J Respir Crit Care Med 2001; 164: 580-584.

46. Soriano JB, Vestbo J, Pride NB, Kiri V, Maden C, Maier WC. Survival in COPD patients after regular use of fluticasone propionate and salmeterol in general practice. Eur Respir J 2002; 20: 819-825.

47. Calverly P, Pauwels R, Vestbo J, et al. for the Trial of Inhaled Steroids and Long-Acting $\beta_{2}$-Agonists Study Group. Combined salmeterol and fluticasone in the treatment of chronic obstructive pulmonary disease: a randomised controlled trial. Lancet 2003; 361: 449-456.

48. Garcia-Aymerich J, Barreiro E, Farrero E, Marrades RM, Morera J, Anto JM. Patients hospitalized for COPD have a high prevalence of modifiable risk factors for exacerbation (EFRAM study). Eur Respir J 2000; 16: 1037-1042. 